\title{
PELANGGARAN LALU LINTAS KENDARAAN BERMOTOR RODA DUA YANG DILAKUKAN OLEH SISWA SEKOLAH MENENGAH PERTAMA, (STUDI KASUS PADA WILAYAH POLRES KABUPATEN TABANAN, DI KOTA TABANAN)
}

\author{
Oleh : \\ Putu Wily Oki Pratiwi \\ Dr.I Gusti Ketut Arya Sunu, M.Pd \\ Drs. I Ketut Sudiatmaka,M.Si \\ Jurusan Pendidikan Pancasila dan Kewarganegaraan \\ Fakultas Ilmu Sosial \\ Universitas Pendidikan Ganesha
}

\begin{abstract}
ABSTRAK
Penelitian ini bertujuan sebagai berikut : (1) Menjelaskan bentuk-bentuk pelanggaran lalu lintas yang dilakukan oleh siswa Sekolah Menengah Pertama (SMP) di Kota Tabanan. (2) Menjelaskan dan memahami faktor-faktor penyebab siswa Sekolah Menengah Pertama (SMP) di Kota Tabanan melakukan pelanggaran lalu lintas. (3) Menjelaskan dan memahami upaya yang dilakukan oleh aparat kepolisian untuk menanggulangi pelanggaran lalu lintas yang dilakukan oleh siswa Sekolah Menengah Pertama (SMP) di Kota Tabanan. (4) menjelaskan alternatif dari pemecahan masalah tersebut.

Penelitian ini secara metodelogis menggunakan pendekatan penelitian deskriptif kualitatif. Subyek penelitian ini adalah Polres Kota Tananan mengenai Pelanggaran Lalu Lintas Kendaraan Bermotor Roda Dua Yang Dilakukan Oleh Siswa Sekolah Menengah Pertama. Tekhnik pengumpulan data yang digunakan adalah metode observasi, wawancara, pencatatan dokumen, dan kuesioner.

Hasil penelitian ini menunjukkan bahwa bentuk pelanggaran lalu lintas diantaranya 1) menggunakan jalan dengan cara yang dapat membahayakan ketertiban atau keamanan lalu lintas. 2) Mengemudikan kendaraan bermotor yang tidak dapat memperlihatkan administrasi, 3) Membiarkan kendaraan bermotor dikemudikan oleh orang lain yang tidak memiliki Surat Izin Mengemudi (SIM). Faktor yang menyebabkan terjadinya hal tersebut adalah faktor internal dan eksternal. Upaya yang dilakukan oleh pihak Sat Lantas Polres Kota Tabanan dalam menanggulangi pelanggaran lalu lintas yang dilakukan oleh siswa Sekolah Menengah Pertama (SMP) dianggap belum maksimal upaya yang dilakukan yakni preventif dan refresif. Alternatif dari pihak kepolisian disini yaiktu untuk menanggulangi atau mengurangi siswa/sisiwi SMP yang membawa sepeda motor
\end{abstract}


kesekolah dengan cara masyarakat, kepolisian, guru serta orang tua siswa/siswi bersatu untuk sama-sama bekerja sama memberantas siswa/siswi yang membawa kendaraan sepeda motor kesekolah.

Kata-Kata Kunci: Pelanggaran, Siswa SMP, Lalu Lintas

\section{Pendahuluan}

Masalah transpotasi di dunia modern kini telah merupakan masalah yang amat esensial. Kebutuhan sarana transportasi bagi masyarakat modern telah menjadi kebutuhan primer, baik di kota-kota besar maupun di pedesaan. Dunia justru semakin sempit karena pesatnya kemajuan di bidang transportasi baik transportasi laut, udara, maupun transportasi di darat. Ketidaksiapan tersebut antara lain nampak misalnya pada kesadaran hukum warga masyarakat dalam menggunakan sarana transportasi darat di jalan-jalan darat. Salah satu faktor yang menunjukkan rendahnya kesadaran hukum masyarakat dalam berlalu lintas adalah dari segi proses penyelesaian pelanggaran lalu lintas.

Sebagai contoh nyata, di sekitar wilayah areal kantor Bupati Tabanan, kantor Camat Tabanan, areal pinggir sekolah SMP Negeri 2 Tabanan, SMP Negeri 3 Tabanan dan seputar jalan krisna dan warkudara menjadi sarang siswa/siswi SMP Negeri 2 Tabanan dan SMP negeri 3 Tabanan untuk memarkir sepeda motornya. Hal tersebut sudah menjadi pemandangan yang biasa yang terjadi setiap jam sekolah oleh warga diseputar wilayah tersebut. Banyak warga diseputar jalan tersebut mengeluhkan fenomena tersebut, karena parkir liar para siswa/siswi tersebut mengganggu jalannya lalu lintas di seputar jalanan tersebut, belum lagi saat jam pulang sekolah. Banyak siswa/siswi yang menongkrong-nongkrong, negebutngebutan dan membawa sepeda motor secara ugal-ugalan tanpa menggunakan helm. Hal tersebut diresahkan warga karena, daerah tersebut merupakan daerah pemerintahan atau kantor-kantor penting di wilayah Kota Tabanan, jadi banyak kendaraan yang yang terganggu saat melewati wilayah tersebut. Kemacetan pun sering terjadi diwilayah tersebut, karena 
parkir sembarang yang dilakukan oleh siswa/siswi SMP tersebut, banyaknya siswa/siswi yang nongkrong dipinggir jalan sembari memarekan motornya.

\section{Metode Penelitian}

Penelitian ini mengguanakan rancangan deskriptif kualitataif. Penelitian deskriptif kualitatif diartikan sebagai suatu penelitian dengan prosedur yang menghasilkan data deskriptif, yang bersumber dari tulisan atau ungkapan tingkah laku yang dapat diobservasi dari manusia (Ashshofa, 1988:16). Dalam penelitian ini, subyek penelitiannya adalah Polres Kota Tananan mengenai Pelanggaran Lalu Lintas Kendaraan Bermotor Roda Dua Yang Dilakukan Oleh Siswa Sekolah Menengah Pertama. Mengacu pada data yang diperlukan dalam mengkaji masalah penelitian ini maka peneliti dalam pencarian data yang diperlukan menggunakan beberapa metode / teknik pengumpulan data, yakni : observasi, wawancara, pencatatan dokumen, dan kuesioner. Dalam mengolah data yang telah didapatkan tentu akan menemui berbagai langkah yang sistematis untuk menyusun datan yang telah diperoleh dalam beberapa tahapantahapan. Dengan demikian cara pengolahannya adalah menghubungkan data yang ada dengan pembahasan untuk diketahui apakah data yang diperoleh sudah adapat menjawab pertanyaanpertanyaan yang muncul dalam penelitian maka peneliti akan melakukan penggalian data yang lebih intensif / lebih mendetail dan lebih mendalami lagi atau lebih mengarah pada sasaran yang dituju.

Cara-cara yang ditempuh diantaranya adalah Tahap pertama yang dilakukan dalam penelitian ini adalah dengan membuat catatancatatan mengenai data yang didapatkan melalui metode-metode pengumpulan data yang telah dibuat dan direncanakan, yakin melalui, obsevasi, kepustakaan, wawancara, pencatatan dokumen, dan kuesioner.

Kemudian tahap kedua yang dilakukan adalah setelah data diperoleh dan terkumpul maka tahap berikutnya adalah membuat deskripsi tentang semua data tersebut agar masalah yang akan diteliti semakin terlihat jelas dan dengan jelasnya 


\begin{abstract}
permasalahan peneliti dapat
melakukan rekonstruksi atau

perbaikan seperti halnya pembuatan

konsep, mencari hubungan sebab akibat yang ada dan melakukan interprestasi data terhadap seluruh data yang telah diperoleh.
\end{abstract}

Tahap ketiga adalah dengan mereduksidata dengan permasalahan yang ingin diketahui jawabnnya, dalam artian mencari jawaban dari apa yang menjadi permasalahan dalam penelitian ini sehingga dapat dibuat suatu kesimpulan dari hasil penelitian sendiri dan kesimpulan tesebut nantinya menjadi hasil akhir dari penelitian ini.

\section{Hasil Penelitian dan}

Pembahasan

3.1 Menjelaskan bentuk-bentuk pelanggaran lalu lintas yang dilakukan oleh siswa Sekolah Menengah Pertama (SMP) di Kota Tabanan

Bentuk-bentuk pelanggaran lalu lintas antara lain: (Wawancara dengan KAU Binop/KBO I Gst Ngurah Bagus Astawa, S.H., tanggal 4 Februari 2014)
1.Menggunakan jalan dengan cara yang dapat membahayakan ketertiban atau keamanan lalu lintas.

2.Mengemudikan kendaraan bermotor yang tidak dapat memperlihatkan Surat Izin Mengemudi (SIM), STNK, Surat Tanda Uji Kendaraan (STUJ) yang sah atau tanda bukti lainnya sesuai peraturan yang berlaku atau dapat memperlihatkan tetapi masa berlakunya sudah kadaluarsa.

3.Membiarkan atau memperkenankan kendaraan bermotor dikemudikan oleh orang lain yang tidak memiliki Surat Izin Mengemudi (SIM).

4.Tidak memenuhi ketentuan peraturan perundangundangan lalu lintas jalan tentang penomoran, penerangan, peralatan, perlengkapan kendaraan.

5.Membiarkan kendaraan bermotor yang ada di jalan tanpa dilengkapi plat tanda 


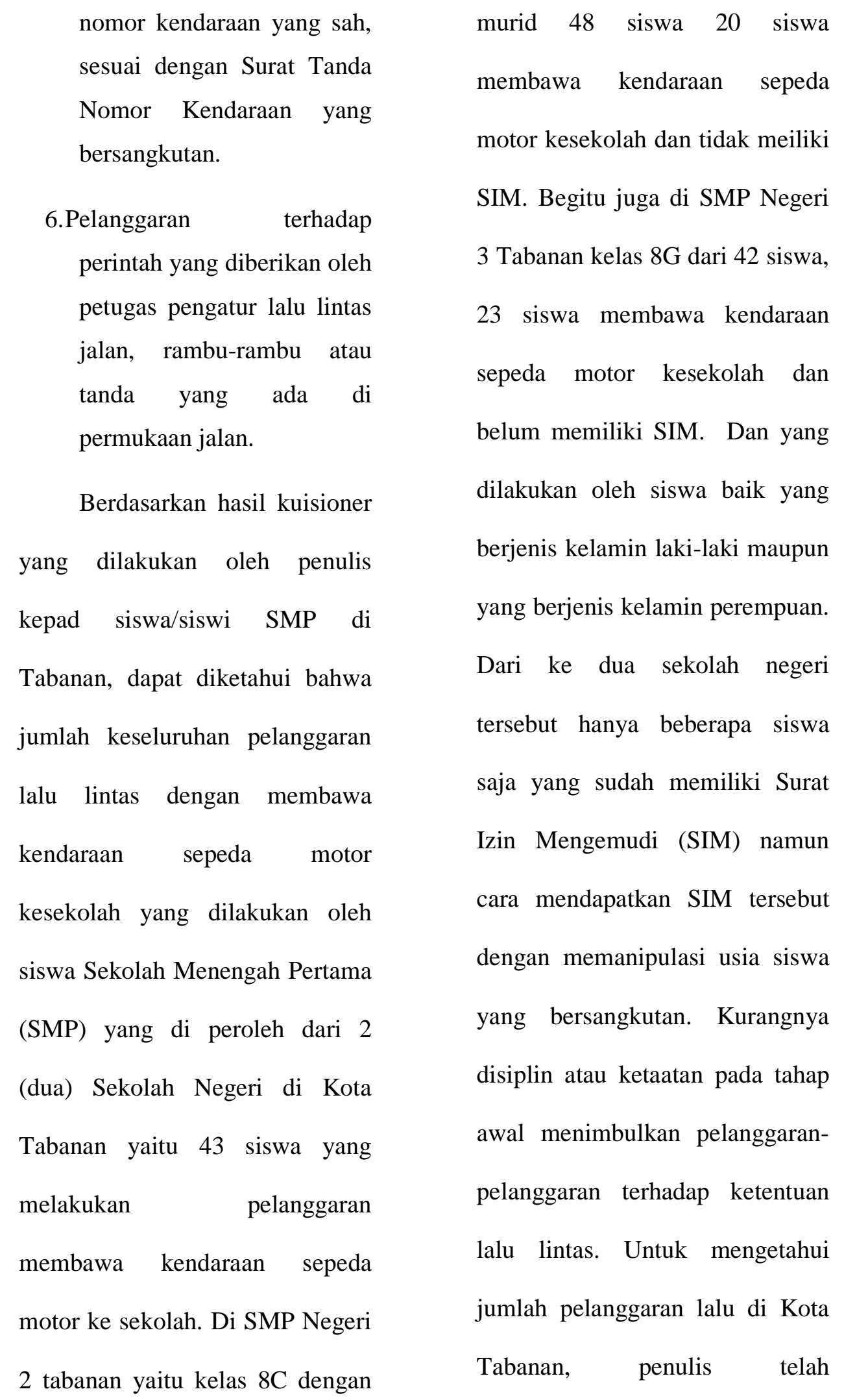




\begin{tabular}{|c|c|}
\hline menguraikannya dalam bentuk & pelanggaran lalu lintas yang \\
\hline abel. Bahwa pelanggaran lalu & dilakukan oleh anak dilihat de \\
\hline lintas yang dilakukan oleh Siswa & tingkat pendidikan yang terjadi \\
\hline Sekolah Menengah Pertma dari & Kota Tabanan dari tahun 2011 \\
\hline tahun 2009 sampai tahun 2011, & sampai dengan tahun 2013 yai \\
\hline tercatat sebanyak & 1822. \\
\hline $\begin{array}{l}\text { pelanggaran. Pada tahun } 2011 \\
\text { sebanyak } 138 \text { pelanggaran atau }\end{array}$ & $\begin{array}{l}\text { 3.2 Faktor-faktor penyebab siswa } \\
\text { Sekolah Menengah Pertama }\end{array}$ \\
\hline $\begin{array}{l}\text { sekitar } 13.87 \% \text {, pada tahun } 2012 \\
\text { mengalami peningkatan sebanyak }\end{array}$ & $\begin{array}{l}\text { Dari hasil penelitian yar } \\
\text { dilakukan oleh penulis, bahv }\end{array}$ \\
\hline 295 pelanggaran atau sekitar & $\begin{array}{lr}\text { faktor-faktor } & \text { terjadiny: } \\
\text { siswa/siswi } & \text { melakukar }\end{array}$ \\
\hline 27.25\%, sedangkan pada tahun & pelanggaran lalu \\
\hline 2013 juga mengalami peningkatan & membawa kendaraan sepeda \\
\hline yaitu sebanyak 599 pelanggaran & $\begin{array}{l}\text { motor kesekolah yang dilakukan } \\
\text { oleh siswa/siswi disebabkan }\end{array}$ \\
\hline $\begin{array}{lrr}\text { atau sekitar } 58.88 \% & \text { Jadi } \\
\text { pelanggaran lalu lintas } & \text { vang }\end{array}$ & $\begin{array}{l}\text { faktor internal dan faktor } \\
\text { external, dimana faktor internal }\end{array}$ \\
\hline dilakukan oleh Siswa Sekolah & $\begin{array}{l}\text { antara lain: faktor ketidak } \\
\text { disiplinan, faktor kealpaan/lupa }\end{array}$ \\
\hline Menengah Pertama (SMP) di & faktor ketidak \\
\hline $\begin{array}{l}\text { Kota Tabanan dari cakupan } 3 \\
\text { (tiga) tahun tersebut dapat dilihat }\end{array}$ & $\begin{array}{l}\text { pahaman/ketidaktahuan, dan } \\
\text { faktor kelalaian. Sedangkan } \\
\text { faktor externalnya diantaranya }\end{array}$ \\
\hline Sesuai dengan data yang & $\begin{array}{l}\text { faktor sarana dan prasarana } \\
\text { jalan, faktor orang tua, faktor } \\
\text { pergaulan bebas. }\end{array}$ \\
\hline
\end{tabular}

telah diperoleh dari Kepolisian

Faktor internal terdiri dari (1)

Sat Lantas Kota Tabanan, tindak 
karena pengaruh dari luar, dimana siswa yang sudah mengetahui peraturan dari sekolah dan polres terkait siswa SMP tidak boleh membawa kendaraan sepeda motor kesekolah, namum karena faktor ketidak disiplinan dan pengaruh dari luar, banyak siswa yang masih melanggar tanpa takut sanksi-sanksi yang akan mereka dapat nantinya. (2) faktor kealpaan/lupa yakni kebanyakan pengendara melupakan hal-hal penting dalam berlalu lintas seperti lupa membawa SIM dan STNK bagi seseorang yang sudah dapat memiliki SIM. (3) factor ketidak pahaman/ketidaktahuan artinya banyaknya pelanggaran yang dilakukan oleh siswa yang tidak mengetahui marka rambu lalu lintas. Siswa/siswi ini biasanya belum memiliki SIM dan mengendarai sepeda motor dengan cara ugal-ugalan dimana banyak masyarakat yang mengeluh akan kejadian ini terutama para staf pemerintahan kota Tabanan, dimana beliau merasa terganggu karena prilaku ugal-ugalan dan parkir liar dari siswa/siswi SMP yang membawa kendaraan sepeda motor roda kesekolah. (4) Faktor kelalaian merupakan salah satu faktor yang sering mengakibatkan terjadinya kecelakaan lalu lintas. Sangatlah jelas bahwa faktor kelalaian siswa di jalan merupakan salah satu faktor pelanggaran lalu lintas. Terutama di seputaran wilayah SMP Negeri 2 dan 3 Tabanan yang letaknya di jantung kota Tabanan dan letaknya diapit oleh kantor pemerintahan kota Tabanan, yang sering terjadi kecelakaan akibat siswa/siswi yang mengendarai sepeda motor denga ugal-ugalan dan parkir liar dari siswa/siswi tersebut yang mengakibatkan kemacetat lalu lintas.

Faktor eksternal terdiri dari (1) Faktor orangtua artinya sebagian besar beralas mereka memilih membawa kendaraan sepeda motor kesekolah diakibatkan karena kedua orang tua mereka yang bekerja pagi dan arah jalur tempat orang tua 
mereka bekerja berlawanan arah atau tidak searah dengan sekolah puta/putri mereka. Maka dari itu orang tua mereka mengijinkan putra/putrinya dengan catatan hati-hati di perjalanan dan tidak ugal-ugalan saat mengendarai sepeda motor. (2) Faktor sarana dan prasarana misalnya saja kondisi jalan yang kurang baik/berlubang, marka rambu maupun alat pemberi isyarat lalu lintas yang kurang baik atau rusak, sehingga pengendara kendaraan bermotor banyak yang melakukan pelanggaran lalu lintas akibat sarana dan prasarana yang tidak memadai. Selain itu faktor yang banyak menyebabkan siswa/siswi membawa klendaraan sepeda motor dimana kurangnya sarana angkutan umum di wilayah rumah mereka. (3) Faktor pergaulan yang sangat bebas disini sangat mempengaruhi banyak siswa/ssiwi melanggar lalu lintas khusunya membawa kendaraan sepeda motor kesekolah. Dimana iya membawa sepeda motor keekolah karena bujuk rayu dan merasa gengsi dari temantemannya.

\subsection{Upaya yang dilakukan oleh} aparat kepolisian untuk menanggulangi pelanggaran lalu lintas yang dilakukan oleh siswa Sekolah Menengah Pertama (SMP) di Kota Tabanan.

$$
\text { Upaya yang dilakukan oleh }
$$
pihak Sat Lantas Polres Kota Tabanan dalam menanggulangi pelanggaran lalu lintas yang dilakukan oleh siswa Sekolah Menengah Pertama (SMP) dianggap belum maksimal, karena dalam hasil operasi terakhir Sat Lantas Polres Kota Tabanan selama tahun 2011 sampai tahun 2013 angka kasus pelanggarannya cukup tinggi. Dalam melaksanakan tugas pokok kepolisian untuk selalu memelihara keamanan, ketertiban, kelancaran lalu lintas, dan menegakkan hukum, serta memberikan perlindungan, pengayoman, dan pelayanan kepada masyarakat.

$\begin{array}{crr}\text { Dalam } & \text { penyelesaian } \\ \text { pelanggaran } & \text { lalu lintas }\end{array}$




$$
\begin{aligned}
& \text { khususnya banyak siswa/siswi } \\
& \text { smp yang membawa sepeda } \\
& \text { motor kesekolah yang dilakukan } \\
& \text { oleh siswa Sekolah Menengah } \\
& \text { Pertama Negeri (SMP) di Kota } \\
& \text { Tabanan lasimnya ditempuh } \\
& \text { dengan prosedur administratif } \\
& \text { yang dilakukan dengan } \\
& \text { mempergunakan surat-surat } \\
& \text { isian (formulir) yang terdiri dari } \\
& \text { beberapa rangkap dan masing- } \\
& \text { masing warna mempunyai } \\
& \text { fungsi. }
\end{aligned}
$$

\subsection{Kendala dan Alternatif Dalam Memecahkan Masalah}

Dari pihak kepolisian disini
yaiktu untuk menanggulangi
atau mengurangi siswa/sisiwi
SMP yang membawa sepeda
motor kesekolah dengan cara
masyarakat, kepolisian, guru
serta orang tua siswa/siswi
bersatu untuk sama-sama
bekerja sama memberantas
siswa/siswi yang membawa
kendaraan sepeda motor
kesekolah. Karena hanya dengan
jalan itu dapat mengurai
siswa/siswi yang membawa
motor kesekolah. Mulai dari
orang tua yang melang tegas

siswa/siswi mereka untuk

membawa sepeda motor

kesekolah, selanjutnya dari

pihak dewan guru juga tegas memberikan sanksi kepada siswa/siswinya agar tidak membawa sepeda motor kesekolah, lalu di masyarakat yang tidak mendukung dengan menyewakan halam atau rumah mereka sebagai tempat penitipan motor. Jika semua komponen ini telah bersatu maka polisi selaku aparat penengak hukum juga akan bertindak lebih tegas dan memberikan sanksi yang lebih tegas jika menemukan siswa/siswi yang menggunakan seram sekolah SMP membawa sepeda motor. (wawancara dengan KAU Binop/KBO I Gst Ngurah Bagus Astawa, S.H. tabanan 4 februari 2014). hambatan yang yang dilalu contohnya salah satunya adalah sifat para siswa yang sudah dilarang besoknya bisa seidikit berubah namun setelah tidak diadakan teguran melakukan hal atau kesalah yang sama kembali. Hal ini terus menerus dilakukan siwa/siswi yang memang dari 
segi umur mereka masuk katagori peralihan dari segi anak-anak ke segi umur remaja. Jadi tidak bisa dipungkiri kenakalan-kenakalan seperti ini rentan terjadi. Semakin dilarang setelah itu akan mulai berubah namun jika dilihat ada celah untuk melanggar sedikit siswa itu pasti akan melakukan hal yang sama atau pelanggaran yang sama. Maka dari Itulah para dewan guru setiap hari senen tidak henti memberi pengarahan dan razia keliling agar siswa/siswi jera untuk membawa sepeda motor kesekolah. (wawancara dengan wakasek kesiswaan SMP N 2 Tabanan Ni Ketut Ariwati, S.Pd, M.Pd)

\section{Penutup}

Sesuai dengan pokok
permasalahan diatas, maka dapat
ditarik kesimpulan bahwa
pelanggaran lalu lintas yang
dilakukan oleh Siswa Sekolah
Menengah Pertma dari tahun
2009 sampai tahun 2011,
tercatat sebanyak 1.032
pelanggaran. Pada tahun 2011

sebanyak 138 pelanggaran atau sekitar $13.87 \%$, pada tahun 2012 mengalami peningkatan sebanyak 295 pelanggaran atau sekitar $27.25 \%$, sedangkan pada tahun 2013 juga mengalami peningkatan yaitu sebanyak 599 pelanggaran atau sekitar $58.88 \%$. Jadi pelanggaran lalu lintas yang dilakukan oleh Siswa Sekolah Menengah Pertama (SMP) di Kota Tabanan dari cakupan 3 (tiga) tahun tersebut dapat dilihat mengalami peningkatan. Berdasarkan data yang diperoleh, dapat diketahui bahwa jumlah pelaku pelanggaran lalu lintas membawa kendaraan sepeda motor roda dua kesekolah di 2(dua ) Sekolah Menengah Pertama Negeri di Kota Tanan berdasarkan jenis pelanggaran (pasal) sebanyak 45 siswa. Pada Pasal 281 (tidak memiliki Surat Izin Mengemudi (SIM) terdapat 30 siswa yang melakukan pelanggaran, Pasal 287(1) (rambu lalu lintas) terdapat 14 siswa yang melakukan pelanggaran, Pasal 288(1) (tidak membawa Surat Tanda Nomor 
Kendaraan Bermotor) terdapat 3 siswa yang melakukan pelanggaran, sedangkan pada Pasal 291(1) (tidak mengenakan helm standar nasional Indonesia) terdapat 12 siswa yang melakukan pelanggaran. Faktor internal dan faktor external, adalah dua faktor yang menyebabkan siswa/siswi membawa kendaraan sepeda motor kesekolah. Dimana faktor internal antara lain: faktor ketidak disiplinan, faktor kealpaan/lupa, faktor ketidak pahaman/ketidaktahuan, dan faktor kelalaian. Sedangkan faktor externalnya diantaranya faktor sarana dan prasarana jalan, faktor orang tua, faktor pergaulan bebas.

Faktor Internal diantaranya a) faktor ketidaksiplinan, b) faktor kealpaan/lupa, c) faktor ketidak pahaman/ketidaktahuan dan faktor kelalaian Faktor external diantaranya faktor orangtua, faktor sarana dan prasarana dan faktor pergaulan bebas. Upaya yang dilakukan oleh pihak Sat Lantas Polres Kota Tabanan dalam menanggulangi pelanggaran lalu lintas yang dilakukan oleh siswa Sekolah Menengah Pertama (SMP) dianggap belum maksimal, karena dalam hasil operasi terakhir Sat Lantas Polres Kota Tabanan selama tahun 2011 sampai tahun 2013 angka kasus pelanggarannya cukup tinggi.

\section{DAFTAR PUSTAKA}

Undang-Undang RI No. 2 Tahun 2002 tentang Kepolisian Negara

Republik Indonesia.

Undang-Undang Nomor 22 Tahun

2009 tentang Lalu Lintas dan

Angkutan Jalan.

A Zainal Abidin Farid. 1995. Hukum

Pidana I. Jakarta: Sinar Grafika.

Fadli Sandi. 2012. Tinjauan

Kriminologis Terhadap

Pelanggaran Lalu Lintas

Mengendrai Kendaraan

beermotor Tanpa dilengkapi

Surat Izin Mengemudi Dikota

Makassar.

Arikunto, Suharsimi. 1989,

Manajemen Penelitian. Jakarta:

Departemen Pendidikan dan

Kebudayaan. Direktorat jenderal

Pendidikan Tinggi. 
Ashshofa, Burhan. 1998. Metode

Penelitian. Jakarta: PT. Rineka Cipta.

Nasution, Andi Hakim. 1992.

Panduan Berfikir dan Meneliti

Secara Ilmiah Bagi Remaja.

Jakarta: PT. Grasindo.

Netra. 1974. Metodologi Penelitian. Singaraja: Biro Penelitian IKIP Unud

Sucipta, I Made. 2009. Pendidikan

Kewarganegaraan (Bahan Ajar

Kelas X Semester I). Singaraja:

Tim Fascom Grafi.

Sugiyono. 2008. Metode Penelitian

Kuantitatif, Kualitatif dan $R \& D$.

Bandung : CV. Alfabeta.

Soekanto, Soerjono. 1998. Pokok-

pokok Sosiologi Hukum. Jakarta:

PT Raja Grafindo Persada.
Soekanto. 1981. Pokok-pokok

Hukum Adat . Alumni Bnadung

Kartono, K. 1986. Psikhologi Anak.

Bandung: Penerbit Alumni

Papalia, Olds \& Fielman.2004.

Human development. New York:

Mc Graw HillInc.

Soekanto, 1982. Sosiologi Hukum

Dalam Masyarakat. Jakarta: C.V.

Rajawali

Tutik, Titik t 2008, Hukum Perdata

Dalam Sistem Hukum Nasional.

Jakarta Kencan Medeia Group

TO, Ihroni. 1984. Antropologi

Hukum. Jakarta: Yayasan Obor

Jakarta 